\title{
Avaliação ambiental de sistemas hidrogeomorfológicos e áreas de preservação permanente em recuperação na Unidade Hidrográfica Rio do Fagundes, Paraíba do Sul, RJ, Brasil
}

\author{
Evaluación ambiental de los sistemas hidrogeomorfológicos \\ y el área de conservación permanente de manantiales en \\ restauración en la Unidad Hidrográfica Rio do Fagundes, \\ Paraíba do Sul, RJ, Brasil
}

\section{Environmental assessment of hydrogeomorphological systems and permanent preservation area of springs in restoration at the 'Rio do Fagundes' Hydrographic Unit, Paraíba do Sul, RJ, Brazil}

Cintia de Andrade Corrêa cintiageoufuerj@gmail.com Universidade do Estado do Rio de Janeiro, UERJ, Rio de Janeiro, RJ

Nadja Maria Castilho da Costa

nadjacastilho@gmail.com Universidade do Estado do Rio de Janeiro, UERJ, Rio de Janeiro, RJ

Resumo: As nascentes são importantes e complexos sistemas hidrogeomorfológios com interação geoecológica na paisagem. Este estudo avalia o nível de perturbação das Áreas de Preservação Permanente de dez nascentes seguindo um Protocolo de Avaliação Rápida numa bacia com uso agropecuário em processo de recuperação de nascentes, aplicado no verão e no inverno de 2017. A maioria das nascentes está impactada pela falta de cobertura vegetal, entre outros $(60 \%)$. Independente da estação, apenas 10 a $20 \%$ apresentaram níveis de impacto julgados naturais. Concluiu-se que o protocolo permitiu uma avaliação de baixo custo, podendo ser replicado.

Palavras-chave: Avaliação de nascentes, Protocolo de Avaliação Rápida, Nível de perturbação de nascentes.

Resumen: Los manantiales son sistemas hidrogeomorfológicos importantes y complejos con interacción geoecológica en el paisaje. Esto estudio evalúa el nivel de perturbación de las Áreas de Preservación Permanente de diez manantiales siguiendo un Protocolo de Evaluación Rápida en una cuenca de uso agropecuario en proceso de recuperación de manantiales que se aplicó en verano e invierno de 2017. La mayoría de los manantiales se ven afectados por la falta de cobertura forestal, entre otros $(60 \%)$. Independiente de la temporada, solo del 10 al 20\% presentaron niveles de impacto considerados naturales. Se concluyó que el protocolo permitió una evaluación de bajo costo y podría ser replicado.

Palabras clave: Evaluación de manantiales, Protocolo de evaluación rápida, Nivel de perturbación de manantiales. 


\begin{abstract}
Springs are important and complex hydrogeomorphological systems with geoecological interaction in the landscape. This study evaluates the disturbance level of the Permanent Preservation Areas of ten springs at one agricultural watershed in restoration following a Rapid Assessment Protocol performed in summer and winter 2017. Most of the springs were impacted by the lack of forest cover, among others $(60 \%)$. Regardless of the season, only 10 a $20 \%$ presented levels of impact considered natural. We concluded that the protocol allowed a low cost evaluation and could be replicated.
\end{abstract}

Keywords: Environmental Assessment of Springs, Rapid Assessment Protocol, Disturbance level of springs.

\title{
INTRODUÇÃO
}

As nascentes são importantes hidrossistemas ambientais e a complexidade das relações dos elementos geológico-geomorfológicos, hidrológicos e geoecológicos na paisagem e para a qualidade ambiental de microbacias hidrográficas deve ser abordada sob a ótica do planejamento ambiental. Apenas as nascentes de cursos d'água perenes e o seu entorno são consideradas, pela Lei 12.651/2012 (BRASIL, 2012), Áreas de Preservação Permanente (APPs).

As APPs são definidas como aquelas “(...) cobertas ou não por vegetação nativa, com a função ambiental de preservar os recursos hídricos, a paisagem, a estabilidade geológica, a biodiversidade, o fluxo gênico de fauna e flora, proteger o solo e assegurar o bem-estar das populações humanas", com o objetivo de garantir a preservação das faixas marginais, do entorno de nascentes, dos topos de morros e de encostas com recomendação de serem preservados cinquenta metros (50 metros) no entorno de nascentes (BRASIL, 2012).

Considerando aspectos referentes ao planejamento e à relevância dos estudos relacionados às nascentes como produtoras de água, pretende-se alertar para a importância de seu inventário e conhecimento, contribuindo para a sua valorização, gestão e proteção adequada, de forma que apoiem os processos de decisão.

No Brasil há importantes trabalhos relacionados aos estudos das nascentes, realizados por Valente e Gomes (2005) e Pinto, Roma e Baliero (2012) e por Felippe e Magalhães Júnior (2009; 2012), estes últimos aplicados a unidades de conservação. Gomes (2014) e Silva et al. (2015) tratam gestão ambiental de recursos hídricos subterrâneos. Nesta breve revisão, verifica-se que o estudo sobre nascentes, seja na literatura brasileira ou estrangeira, exige uma abordagem interdisciplinar e geossistêmica, dado a complexidade destes ambientes que subsidiam estudos mais precisos (PASSOS, 2003).

Neste sentido, o objetivo deste trabalho é avaliar as nascentes e o seu entorno em uma microbacia hidrográfica com uso agropecuário e cobertura vegetal com predomínio de pastagem, como também, avaliar e adaptar um protocolo de avaliação rápida (PAR) na Unidade de Planejamento Rio do Fagundes - UHP Rio do Fagundes. 


\section{ÁREA DE ESTUDO}

A UHP Rio do Fagundes possui uma extensão de 2.975,72 hectares, localizados ao sul do município de Paraíba do Sul, no estado do Rio de Janeiro. Este município pertence à Região Centro-sul Fluminense e à região hidrográfica do Rio Piabanha, um dos principais afluentes do Rio Paraíba do Sul (Fig. 1).

Figura 1: UHP do Rio do Fagundes, Paraíba do Sul, RJ e a localização das dez nascentes estudadas

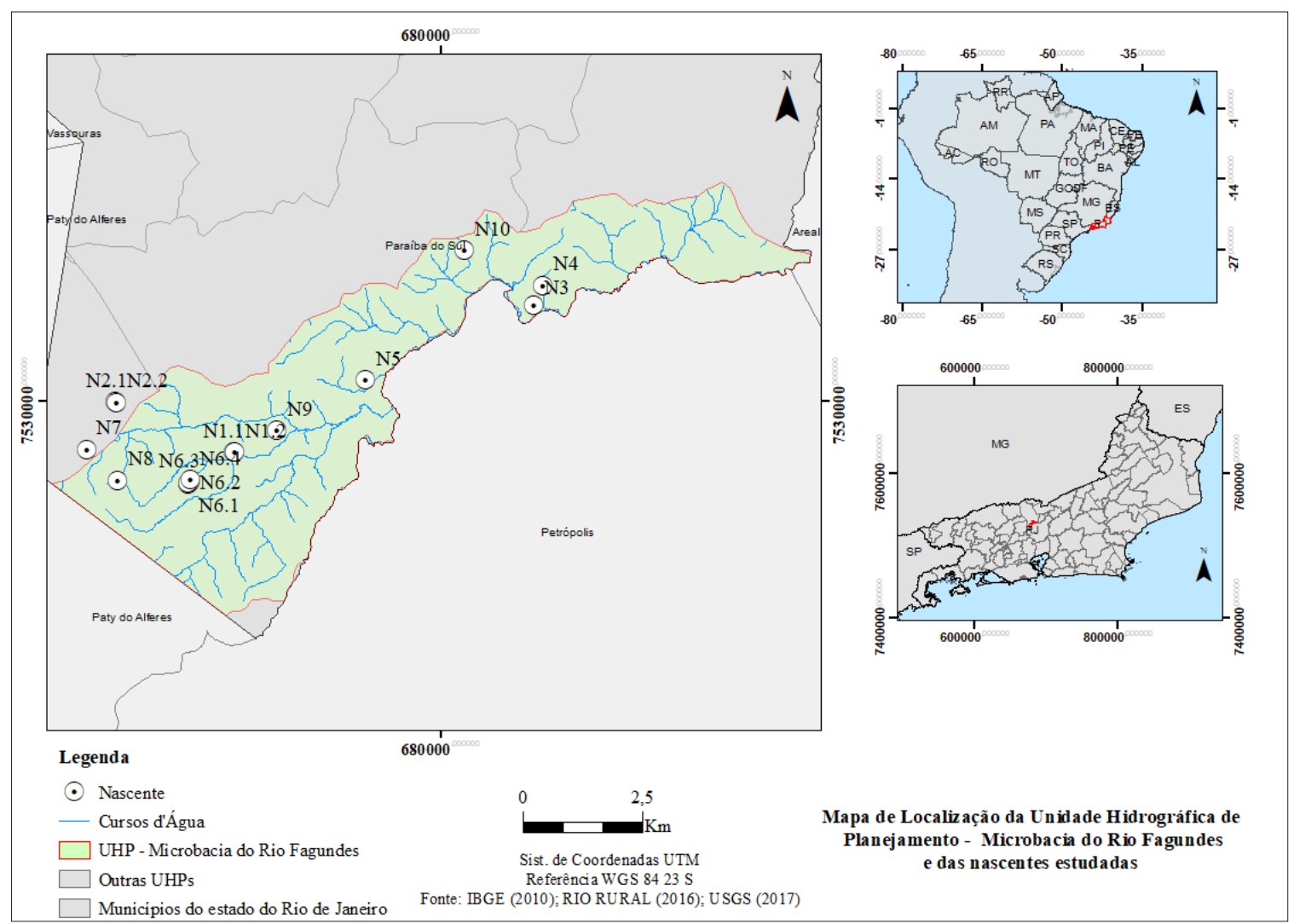

Fonte: as autoras

Pertencente ao "domínio morfoclimático dos mares de morros " (AB'SABER, 2005, p. 29), que conservam resquícios de Floresta Ombrófila Densa nos topos de morros desenvolvidos sobre rochas cristalinas pré-cambrianas de natureza essencialmente granito-gnáissica (DANTAS et al., 2000). Em termos geomorfológicos, caracteriza-se por colinas, morros e serras isoladas locais, em altitude aproximada de 700 metros (INEA, 2011). O clima é do tipo Aw, segundo a classificação de Koeppen, com verões quentes e chuvosos e invernos secos, típicos do clima tropical. $\mathrm{Na}$ área predominam Latossolos e Cambissolos (INEA, 2011; DANTAS et al., 2000).

Nesta UHP foram estudadas dez nascentes autodeclaradas ${ }^{1}$ pelos produtores rurais da UHP e as Áreas de Preservação Permanente de entorno de nascentes definidas pelo

1 Nascente autodeclarada, denominada como 'nascente', indicada para ser protegida pelo proprietário da terra e classificada segundo metodologia empregada por Castro e Gomes (2001); Felippe (2009) e Felippe e Magalhães Jr. (2012). 
artigo 4 , Lei 12.651/2012 (BRASIL, 2012), em processo de recuperação e proteção pelo Programa Estadual Rio Rural2 de Desenvolvimento Rural Sustentável em Microbacias Hidrográficas Sustentabilidade e Proteção de Nascentes (SEAAPI, 2015).

\section{PROTOCOLOS DE AVALIAÇÃO RÁPIDA}

Os Protocolos de Avalição Rápida - PARs, são ferramentas para análise integrada dos ecossistemas que, através de inspeção visual das características do habitat, avalia e valora o grau de perturbação em escores preestabelecidos, determinando a qualidade ambiental (OLIVEIRA; NUNES, 2015). O PAR utiliza informações qualitativas para um diagnóstico ambiental e monitoramento ambiental (BIZZO; MENEZES; ANDRADE, 2014), tendo como base parâmetros de fácil entendimento que consideram a análise integrada através de uma metodologia simplificada de rápida aplicação (RODRIGUES; MALAFAIA; CASTRO, 2008; CALLISTO; MORENO; BARBOSA, 2001a; VARGAS; FERREIRA JÚNIOR, 2012).

Assim, a caracterização do hábitat presente nos Protocolos de Avaliação Rápida de integridade ambiental não está restrita aos parâmetros físico-químicos que definem os padrões de qualidade da água. Portanto, nesse enfoque, a alteração desses parâmetros "não reflete necessariamente as respostas das comunidades biológicas às alterações do ambiente, estando a integridade dessas comunidades muito mais associadas à integridade do habitat" (MINATTI-FERREIRA; BEAUMORD, 2006, p. 5).

Segundo Bizzo, Menezes e Andrade (2014) e Rodrigues, Malafaia e Castro (2008), nos Estados Unidos, em meados de 1980 métodos de avaliação qualitativos foram definidos por órgãos ambientais visando reduzir o alto custo e demora do monitoramento ambiental baseado em análises quantitativas. Estudos referentes à qualidade da água foram desenvolvidos em 1986 pela EPA (Environmental Protection Agency) e pelas agências de monitoramento de águas superficiais, resultando, em 1987, no relatório Surface Water Monitoring: A Framework for Change, que estabelecia a reestruturação dos programas de monitoramento e o auxílio no desenvolvimento de pesquisas com baixos custos, incluindo o desenvolvimento dos Protocolos de Avaliação Rápida (RODRIGUES; MALAFAIA; CASTRO, 2008).

Ainda segundo Rodrigues, Malafaia e Castro (2008), foi publicado por Plafkin et al. (1989) um documento destacando os primeiros PARs desenvolvidos pela Divisão de Avaliação e Proteção das Bacias Hidrográficas, criados para fornecer dados básicos sobre a vida aquática, para fins de qualidade da água e gerenciamento de recursos hídricos (SILVEIRA, 2004).

No Brasil, estudos como os de Callisto, Moreno e Barbosa (2001a), Callisto, Moretti e Goulart (2001b) e Callisto 2002), Carreño (2012), Upgren (2004), Minatti-Ferreira e Beaumord (2006), Ferreira e Beaumord (2008), Rodrigues, Malafaia e Castro (2008), adaptado por Carreño e Botelho (2011) e Duarte (2013) utilizaram PARs para caracterização qualitativa de rios.

2 Programa de Desenvolvimento Rural Sustentável, premiado, segundo a Organização de Agricultura e Alimentação das Nações Unidas - FAO, como a 9a iniciativa mais inovadora para o desenvolvimento da América Latina e Caribe (FAO, 2018). 
Fernández e Raven (2011, p. 4) ressaltam que a escolha dos parâmetros avaliados está intrinsecamente relacionada ao objetivo, desta forma adaptações do protocolo devem ser consideradas para melhor enquadramento ao ambiente de pesquisa. De acordo com Callisto (2002), os resultados dos PARs devem representar o bom entendimento do protocolo, a fácil aplicação e a definição clara da metodologia de avaliação. Ao mesmo tempo, ainda, deve refletir a constante interação com a paisagem e com a abordagem físico-química e a biológica, as quais contribuem para avaliação ambiental (RODRIGUES; MALAFAIA; CASTRO, 2008). Em síntese, o desenvolvimento de um protocolo de avaliação da integridade ambiental de ecossistemas leva em consideração aspectos físicos do hábitat (MINATTI-FERREIRA; BEAUMORD, 2006).

A adaptação, avaliação, aplicação e a apresentação do PAR utilizado neste estudo para o ambiente de APPs de entorno de nascentes (Quadro 1) seguiu Callisto (2002), modificado do protocolo da Agência de Proteção Ambiental de Ohio, EUA (EPA, 1987) e de Vargas e Ferreira Júnior (2012). Foram selecionados 14 parâmetros baseados em características de microbacias de uso rural, com destaque para o nível de impactos ambientais decorrentes de atividades agropecuárias e maior ênfase à qualidade da água, à erosão e à cobertura vegetal e grau de proteção oferecido às APPs de nascentes. Foram levadas em consideração as características da área de estudo previamente avaliadas em campo, acesso aos produtores e as nascentes, entre os anos de 2015 e 2016 e avaliações de Moura et al. (2014).

Quadro 1: Protocolo de Avaliação Rápida das nascentes e APPs de entorno de nascente na UHP Rio do Fagundes.

\begin{tabular}{|c|c|c|c|c|}
\hline \multirow{2}{*}{ Parâmetros } & \multicolumn{4}{|c|}{ Pontuação } \\
\hline & 5 pontos & 3 pontos & 2 pontos & 0 ponto \\
\hline 1. Cobertura & Vegetação natural. & Reflorestamento & $\begin{array}{l}\text { Pastagem/ agricultura/ } \\
\text { monocultura. }\end{array}$ & Solo exposto. \\
\hline $\begin{array}{l}\text { 2. Acesso às } \\
\text { nascentes. }\end{array}$ & $\begin{array}{l}\text { Muito difícil acesso } \\
\text { devido a condições de } \\
\text { proteção desta. }\end{array}$ & $\begin{array}{c}\text { Difícil acesso, entretanto, o } \\
\text { atual processo de proteção } \\
\text { não ajuda ainda no acesso à } \\
\text { nascente. }\end{array}$ & $\begin{array}{l}\text { Média dificuldade, devido } \\
\text { à trilha ou ao caminho } \\
\text { de acesso, ou devido à } \\
\text { declividade ou à altitude. }\end{array}$ & Com acesso. \\
\hline $\begin{array}{l}\text { 3. Qualidade visual } \\
\text { da água da nascente. }\end{array}$ & Transparente. & Turva. & Opaca ou colorida. & $\begin{array}{l}\text { Completamente } \\
\text { ausente. }\end{array}$ \\
\hline 4. Uso da nascente. & $\begin{array}{l}\text { Nascente perene; } \\
\text { uso constante para } \\
\text { abastecimento da } \\
\text { propriedade. }\end{array}$ & $\begin{array}{l}\text { Nascente intermitente; uso } \\
\text { esporádico - apenas durante } \\
\text { e/ou parte do ciclo agrícola. }\end{array}$ & $\begin{array}{c}\text { Nascente efêmera; não há } \\
\text { uso da água. }\end{array}$ & $\begin{array}{l}\text { Ausência de água; } \\
\text { não há uso. }\end{array}$ \\
\hline $\begin{array}{l}\text { 5. Proteção da } \\
\text { nascente }\end{array}$ & $\begin{array}{l}\text { Nascente } \\
\text { completamente } \\
\text { protegida por cerca ou } \\
\text { similar. }\end{array}$ & $\begin{array}{l}\text { Nascente parcialmente } \\
\text { protegida por cerca ou } \\
\text { similar. }\end{array}$ & $\begin{array}{l}\text { Nascente não protegida por } \\
\text { cerca ou similar. }\end{array}$ & $\begin{array}{c}\text { Nascente não } \\
\text { protegida por cerca } \\
\text { ou similar. E ainda } \\
\text { completamente } \\
\text { seca/sem água. }\end{array}$ \\
\hline $\begin{array}{l}\text { 6. Composição e } \\
\text { característica da } \\
\text { mata ciliar no raio } \\
\text { de } 50 \text { metros. }\end{array}$ & $\begin{array}{l}\text { Acima de } 90 \% \text { com } \\
\text { vegetação nativa, } \\
\text { incluindo árvores, } \\
\text { arbustos. Mínima } \\
\text { evidência de } \\
\text { deflorestamento }\end{array}$ & $\begin{array}{c}\text { Entre } 70 \text { e } 90 \% \text { com } \\
\text { vegetação nativa. } \\
\text { Deflorestamento evidente, } \\
\text { mas não afetando o } \\
\text { desenvolvimento da } \\
\text { vegetação. }\end{array}$ & $\begin{array}{l}\text { Entre } 50 \text { e } 70 \% \text { com } \\
\text { vegetação nativa. } \\
\text { Deflorestamento óbvio; } \\
\text { trechos com solo exposto. }\end{array}$ & $\begin{array}{l}\text { Menos de } 50 \% \text { da } \\
\text { mata ciliar nativa. } \\
\text { Desflorestamento } \\
\text { muito acentuado } \\
\text { com solo exposto. }\end{array}$ \\
\hline $\begin{array}{l}\text { 7. Extensão de mata } \\
\text { ciliar. }\end{array}$ & $\begin{array}{l}\text { Largura da faixa de } \\
\text { vegetação maior que } \\
50 \text { m; sem influência } \\
\text { antrópica. }\end{array}$ & $\begin{array}{l}\text { Largura da faixa de } \\
\text { vegetação entre } 30 \text { e } 50 \\
\text { m; mínima influência } \\
\text { antrópica. }\end{array}$ & $\begin{array}{c}\text { Largura da faixa de } \\
\text { vegetação entre } 10 \text { e } 20 \text { m; } \\
\text { influência antrópica intensa. }\end{array}$ & $\begin{array}{c}\text { Largura da faixa de } \\
\text { vegetação inferior } \\
\text { a } 10 \text { m; atividade } \\
\text { antrópica. }\end{array}$ \\
\hline
\end{tabular}


Conclusão

\begin{tabular}{|c|c|c|c|c|}
\hline \multirow{2}{*}{ Parâmetros } & \multicolumn{4}{|c|}{ Pontuação } \\
\hline & 5 pontos & 3 pontos & 2 pontos & 0 ponto \\
\hline $\begin{array}{l}\text { 8. Estabilidade no } \\
\text { raio de } 50 \text { metros. }\end{array}$ & $\begin{array}{c}\text { Estáveis. Erosão } \\
\text { mínima ou ausente; } \\
\text { pequeno potencial para } \\
\text { problemas futuros. }\end{array}$ & $\begin{array}{l}\text { Moderadamente estável. } \\
\text { Pequenas áreas de erosão. } \\
\text { Entre } 0 \text { e } 30 \% \text { do raio com } \\
\text { erosão. }\end{array}$ & $\begin{array}{c}\text { Moderadamente instável. } \\
\text { Entre } 30 \text { e } 60 \% \text { da margem } \\
\text { com erosão. Risco elevado de } \\
\text { erosão. }\end{array}$ & $\begin{array}{c}\text { Instável. Área com } \\
\text { erosão óbvia entre } \\
60 \% \text { e } 100 \% \text { do } \\
\text { raio. }\end{array}$ \\
\hline $\begin{array}{l}\text { 9. Estabilidade de } \\
\text { margens }\end{array}$ & $\begin{array}{c}\text { Estáveis. } \\
\text { Evidência de erosão } \\
\text { mínima ou ausente; } 30 \% \\
\text { da margem com erosão. }\end{array}$ & $\begin{array}{c}\text { Moderadamente instável. } \\
\text { Entre } 30 \text { e } 60 \% \text { da margem } \\
\text { com erosão. Risco elevado } \\
\text { de erosão devido a cortes do } \\
\text { relevo. }\end{array}$ & $\begin{array}{l}\text { Instável. Erosão óbvia entre } \\
\quad 60 \text { e } 90 \% \text { da margem. }\end{array}$ & $\begin{array}{l}\text { Muito instável. } \\
\text { Erosão de 100\%. }\end{array}$ \\
\hline $\begin{array}{l}\text { 10. Fonte pontual de: } \\
\text { lixo doméstico; } \\
\text { embalagem de } \\
\text { agrotóxicos; } \\
\text { resíduos de lavoura; } \\
\text { dejetos animais; } \\
\text { despejo de efluentes } \\
\text { líquidos; material } \\
\text { flutuante. }\end{array}$ & Ausente. & $\begin{array}{l}\text { Ausente no raio de } 50 \mathrm{~m} ; \\
\text { presente nas proximidade } \\
\quad \text { (entre } 51 \mathrm{~m} \text { e } 100 \mathrm{~m}) .\end{array}$ & $\begin{array}{l}\text { Presente. Presença de } \\
\text { material líquido e/ } \\
\text { ou flutuante de origem } \\
\text { doméstica, agrícola e/ou } \\
\text { pecuária, no raio de } 50 \mathrm{~m}\end{array}$ & $\begin{array}{l}\text { Presente. APP/ } \\
\text { nascente, o raio } \\
\text { de } 50 \mathrm{~m} \text {, é o local } \\
\text { de descarte/ } \\
\text { lançamento de } \\
\text { todos os itens } \\
\text { descritos. }\end{array}$ \\
\hline $\begin{array}{l}\text { 11. Presença de } \\
\text { uso agrícola e/ou } \\
\text { pecuário na APP. }\end{array}$ & Ausente. & Raro. & Frequente. & $\begin{array}{l}\text { Presente, ou seja, } \\
\text { a APP é utilizada } \\
\text { para tal fim. }\end{array}$ \\
\hline $\begin{array}{l}\text { 12. Processo de } \\
\text { proteção e/ou } \\
\text { recuperação da } \\
\text { nascente e da APP } \\
\text { com cerca de arame, } \\
\text { cerca viva, estaca, } \\
\text { bambu ou outro. }\end{array}$ & $\begin{array}{c}\text { Presente. } \\
\text { Completamente } \\
\text { implantada, a nascente } \\
\text { dá sinais de pronta } \\
\text { recuperação. }\end{array}$ & \begin{tabular}{|c|} 
Parcial. \\
Em processo de \\
recuperação. \\
Já implantado o processo de \\
isolamento da APP.
\end{tabular} & $\begin{array}{c}\text { Em processo. Ainda não } \\
\text { iniciou o isolamento, mas } \\
\text { a técnica de proteção já foi } \\
\text { eleita e há documentação } \\
\text { comprobatória dos materiais } \\
\text { adquiridos para tal. }\end{array}$ & Inexistente \\
\hline 13.Status da APP. & $\begin{array}{l}\text { A APP está protegida } \\
\text { sem uso agropecuário. }\end{array}$ & $\begin{array}{l}\text { A APP está em processo } \\
\text { de recuperação e/ou } \\
\text { regeneração, e os processos } \\
\text { para tal estão ocorrendo. }\end{array}$ & $\begin{array}{c}\text { Completamente } \\
\text { desprotegida e em alguns } \\
\text { casos não existe cobertura na } \\
\text { proximidade ou na APP. }\end{array}$ & $\begin{array}{l}\text { Completamente } \\
\text { desprotegida e, em } \\
\text { alguns casos, não } \\
\text { existe cobertura na } \\
\text { proximidade, ou na } \\
\text { APP. Ocupada por } \\
\text { uso agropecuário. }\end{array}$ \\
\hline $\begin{array}{l}\text { 14. Status da } \\
\text { nascente. }\end{array}$ & $\begin{array}{c}\text { Recuperada. O } \\
\text { modelo implantado } \\
\text { para a recuperação } \\
\text { da área degradada } \\
\text { foi considerado, até } \\
\text { o presente momento, } \\
\text { muito eficiente, por } \\
\text { propiciar a proteção } \\
\text { do solo e a ativação do } \\
\text { processo de regeneração } \\
\text { no processo de } \\
\text { recuperação da mata } \\
\text { ciliar que recobre a } \\
\text { nascente, tendo em } \\
\text { vista a sua recuperação } \\
\text { e proteção completa } \\
\text { como a garantia de } \\
\text { oferta de água. Com esta } \\
\text { descrição, o nível de } \\
\text { perturbação é natural. }\end{array}$ & \begin{tabular}{|} 
Recuperada. O modelo \\
implantado para a \\
recuperação da área \\
degradada foi considerado, \\
até o presente momento, \\
eficiente. Entretanto, a \\
ativação do processo de \\
regeneração tendo em \\
vista a sua recuperação e \\
proteção precisa avançar. \\
A nascente, bem como a \\
APP, precisa efetivamente \\
ser protegida no raio de 50 \\
metros para garantir a oferta \\
e a quantidade de água. O \\
processo de proteção da \\
nascente é comprometido \\
com o uso da terra até o \\
presente momento. Com \\
esta descrição, o nível \\
de perturbação é pouco \\
alterado.
\end{tabular} & $\begin{array}{c}\text { Não recuperada. O } \\
\text { modelo implantado para } \\
\text { a recuperação da área } \\
\text { degradada foi considerado, } \\
\text { até o presente momento, } \\
\text { pouco aceitável. Entretanto, } \\
\text { a proteção correta, devido } \\
\text { à ausência de técnicas para } \\
\text { tal, não é, até o momento, } \\
\text { aplicada. O uso da terra } \\
\text { contribui para o nível de } \\
\text { perturbação. Impactos } \\
\text { visíveis de desmatamento } \\
\text { e solo degradado e/ } \\
\text { ou compactado. Com } \\
\text { esta descrição, o nível de } \\
\text { perturbação é alterado. }\end{array}$ & $\begin{array}{l}\text { Não recuperada. } \\
\text { O modelo } \\
\text { implantado para } \\
\text { a recuperação da } \\
\text { área degradada } \\
\text { foi considerado } \\
\text { insuficiente e/ou } \\
\text { inaceitável, com } \\
\text { os impactos de } \\
\text { desmatamento, } \\
\text { pisoteio, uso da } \\
\text { terra e degradação } \\
\text { do solo sendo } \\
\text { negativa perante } \\
\text { a avaliação de um } \\
\text { geógrafo/ analista } \\
\text { ambiental. Com } \\
\text { esta descrição, } \\
\text { o nível de } \\
\text { perturbação é } \\
\text { impactado. }\end{array}$ \\
\hline & & $\begin{array}{c}\text { Pontuação Nível de Perturb } \\
0 \text { - } 28 \text { Impactado } \\
30-42 \text { Alterado } \\
44-70 \text { Natural }\end{array}$ & & \\
\hline
\end{tabular}

Fonte: adaptado de Callisto (2002) e de Vargas e Ferreira Júnior (2012). 


\section{RESULTADOS E DISCUSSÕES}

No "PAR verão 2017" (Gráfico 1), 60\% das nascentes (N1, N2, N3, N4, N8 e N9) foram classificadas como impactadas, apresentando pontuações entre 0 e 28 pontos, enquanto $10 \%$ das nascentes (N7), foram classificadas como alteradas, e 20\% (N5 e N6) foram enquadradas em nível de perturbação natural, com pontuações de 70 e 48 pontos.

Gráfico 1: Resultado final da pontuação do "PAR verão 2017". A: pontuação; B: percentual do nível de perturbação das nascentes avaliadas.

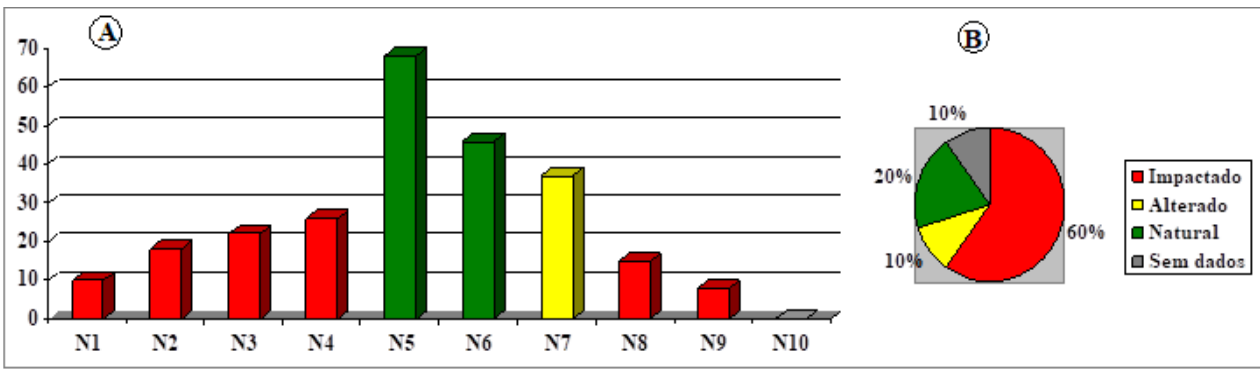

Legenda: Pontuação de 0 - 28, nível de perturbação impactado; pontuação de 30 - 42, nível de perturbação alterado; pontuação de 44 - 70, nível de perturbação natural.

Fonte: as autoras.

No "PAR inverno 2017" (Gráfico 2), com pontuação entre 36 e 38 pontos foram $20 \%$ de ambientes alterados (N6, N7), os mesmos 60\% como impactados (N1, N2, N3, N4, N8 e N9) e apenas a estações N5 (10\%) como estando perturbada naturalmente.

Gráfico 2: Resultado final da pontuação do "PAR inverno 2017". A: pontuação; B: percentual do nível de perturbação das nascentes avaliadas.

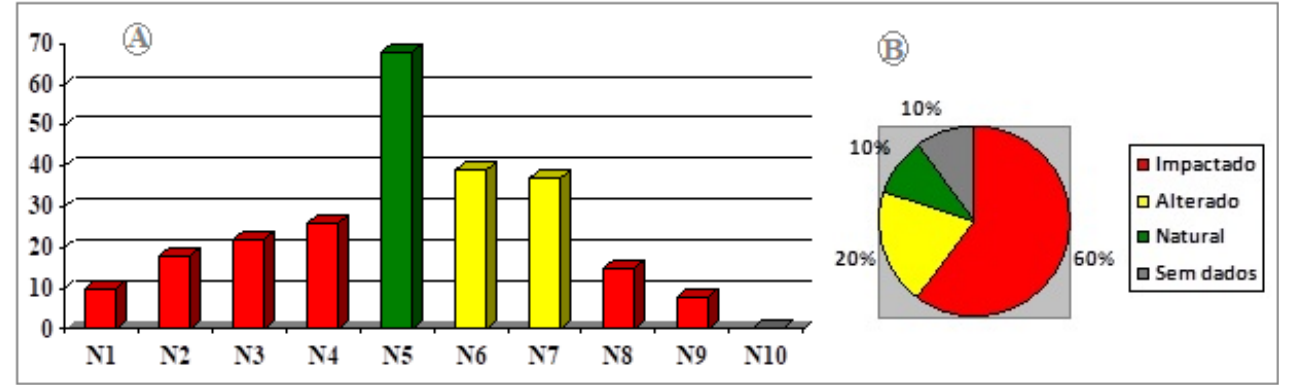

Legenda: Pontuação de 0 - 28, nível de perturbação impactado; pontuação de 30 - 42, nível de perturbação alterado; pontuação de 44 - 70, nível de perturbação natural.

Fonte: as autoras.

Esses dados sugerem que as estações do ano não interferiram, significantemente, nos valores obtidos durante a aplicação dos protocolos, e sim o nível de proteção como o desflorestamento que ocorreu devido a invasão e pisoteio de animais de grande porte entre os períodos, que contribuiu em alguns casos, como na nascente N6, que mudou de 'natural' para 'alterado'. A Figura 2 demonstra os níveis de perturbação 'impactado' (N9), 'alterado' (N6) e 'natural' (N5) encontrados. 
Figura 2: As nascentes estudadas com nível de perturbação 'impactado' (N9 - A; N1 - D), 'alterado' (N6 - C; N7 - E) no "PAR verão" e 'natural' (N5 - B) no "PAR verão" e no "PAR inverno".

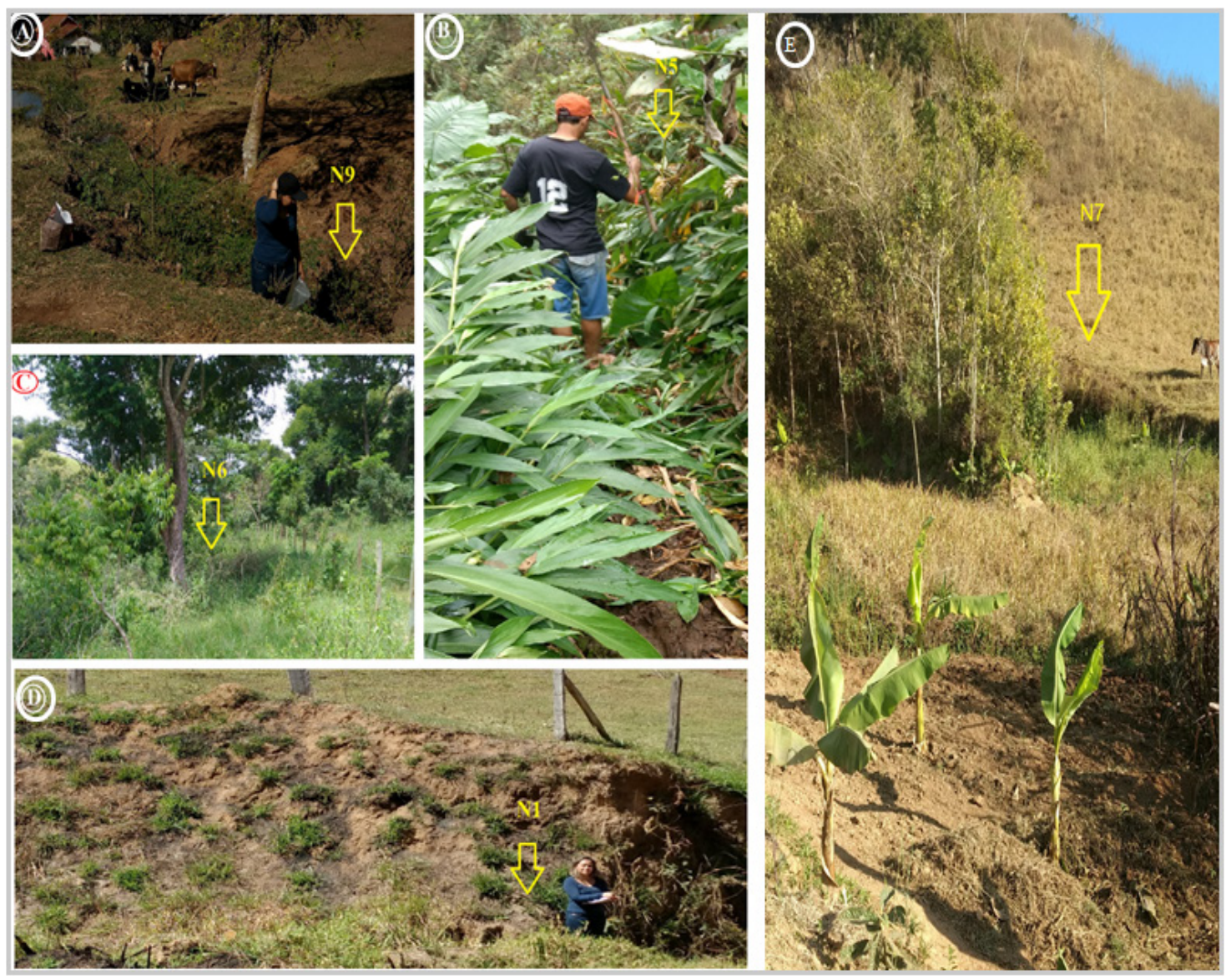

Fonte: as autoras.

A avaliação realizada pelo PAR apresentou como resultados um elevado percentual de ambientes classificados como alterados e impactados, o que correspondeu a, respectivamente, 70\% e 80\% das nascentes avaliadas pelo “PAR verão 2017" e pelo “PAR inverno 2017".

\section{CONSIDERAÇÕES FINAIS}

A avaliação das nascentes e das Áreas de Preservação Permanente e seu entorno revelou que a maioria estava com nível de perturbação impactado ou alterado, tanto no verão quanto no inverno, evidenciando a falta de proteção nas APPs.

Destarte, para a aplicação de estudos relacionados à qualidade ambiental que avalie microbacias hidrográficas ao nível de UHP, as nascentes e as áreas de preservação permanente de entorno de nascentes, o Protocolo de Avaliação Rápida foi essencial. Este permitiu de uma forma viável, rápida e de baixo custo, a análise qualitativa considerando a água, o solo, a cobertura florestal, a nascente e a APP, de forma sistêmica.

Assim, o presente trabalho aponta um caminho a ser seguido, a partir de um estudo de caso, que poderá nortear outros estudos relacionados à avaliação de nascentes e o entorno com uso de Protocolos de Avaliação Rápida. 


\section{REFERÊNCIAS}

AB'SÁBER, Aziz N. Os Domínios da Natureza do Brasil: potencialidades paisagísticas. São Paulo: Ateliê Editorial, 2005.

BIZZO, Myrella R.O.; MENEZES, Juliana, ANDRADE, Sandra F. de. Protocolos de Avaliação Rápida de Rios (PAR). Caderno de Estudos Geoambientais, v. 4, n. 1, p. 5-13, 2014.

BRASIL. Lei $\mathbf{n}^{0}$ 12.651, de 25 de maio de 2012. Institui o Novo Código Florestal. Diário Oficial da União, 28 maio 2012.

CALLISTO, Marcos. Aplicação de um protocolo de avaliação rápida da diversidade de habitats em atividades de ensino e pesquisa (MG-RJ). Acta Limnologica Brasiliensis, v. 14, n. 1, p. 91-98, 2002.

; MORENO, Pablo; BARBOSA, Francisco A.R. Habitat diversity and benthic functional trophic groups at Serra do Cipó, Southeast Brazil. Rev. Bras. Biol., v. 61, n. 2, p. 259-266, 2001 a.

; MORETTI, M.; GOULART, M.D.C. Macroinvertebrados bentônicos como ferramenta para avaliar a saúde de riachos. Revista Brasileira de Recursos Hídricos, v. 6, n.1, p. 71-82, 2001b.

CARREÑO, Paloma M.L.P. Avaliação quali-quantitativa das águas da bacia do Alto Rio Preto - região de Visconde de Mauá (RJ/MG). Rio de Janeiro, 2012. Monografia (Especialização em Análise Ambiental e Gestão do Território) - Escola Nacional de Ciências Estatísticas, ENCE.

; BOTELHO, Rosângela Garrido M. A contribuição do método qualitativo para a avaliação da saúde dos corpos hídricos: a aplicação do PAR na bacia do Alto Rio Preto. In: CONGRESSO BRASILEIRO DE LIMNOLOGIA, 13, 2011, Natal. Anais ...

CASTRO, Paulo S.; GOMES, Marcos Antonio. Técnicas de conservação de nascentes. Ação Ambiental, v. 4, n. 20, p. 24-26, out./nov. 2001.

DANTAS, Marcelo; SHINZATO, Edgar; MEDINA, Antonio Ivo M. et al. Diagnóstico Geoambiental do Estado do Rio de Janeiro. 2000. Serviço Geológico do Brasil/CPRM - Portal do Governo do Estado do Rio de Janeiro. Disponível em: rigeo.cprm.gov.br/jspui/bitstream/doc/.../14/rel_proj_rj_geoambiental.pdf. Acesso em: 11 nov. 2017.

FAO - Organización de las Naciones Unidas para la Alimentación y la Agricultura. Regional Office for Latin America and the Caribbean. Disponível em: www.fao.org Acesso em: 20 ago. 2018.

FELIPPE, Miguel Fernandes. Caracterização e tipologia de nascentes em unidades de conservação de Belo Horizonte com base em variáveis geomorfológicas, hidrológicas e ambientais. Belo Horizonte, 2009. Dissertação (Mestrado em Geografia e Análise Ambiental) - Universidade Federal de Minas Gerais, UFMG.

; MAGALHÃES JÚNIOR, Antonio P.M. Impactos ambientais macroscópicos e qualidade das águas em nascentes de parques municipais em Belo Horizonte - MG. Geografias, v. 8, n. 2, p. 8-23, 2012.

FERNÁNDEZ, Diego; RAVEN, Paul J. A review of river habitat characterization methods: indices vs. characterization protocols. Limnetica, v. 30, n. 2, p. 217-234, 2011.

FERREIRA, Morgana F.; BEAUMORD, Antonio C. Mapeamento da sensibilidade ambiental à derrames de óleo nos cursos de água da bacia do rio Canhandura, Itajaí, SC. Braz. J. Aquat. Technol., v.12, n.2, p. 61-72, 2008.

GOMES, Rui. Recursos hídricos subterrâneos: inventário, cartografia SIG, metodologia e potencialidades - caso de estudo: bacia da Ribeira de Sá, Sardoura, Castelo de Paiva. Porto, 2014. Dissertação (Mestrado em Sistemas de Informação Geográfica) - Universidade do Porto, Portugal.

INEA - Instituto Estadual do Ambiente. O estado do ambiente: indicadores ambientais do Rio de Janeiro. Organizadoras: Júlia Bastos e Patrícia Napoleão. Rio de Janeiro, 2011. Disponível em <inea.gov.rj.br> Acesso em: 19 out. 2017.

MINATTI-FERREIRA, Denize D.; BEAUMORD, Antonio Carlos. Adequação de um protocolo de avaliação rápida de integridade ambiental para ecossistemas de rios e riachos: aspectos físicos. Revista Saúde Ambiental, v. 7, n. 1, p. 39-47, 2006. 
MOURA, Mirela N; ALVES, Mário J.; DIAS, Johnny de S. et al. Grau de alteração ambiental dos hidrossistemas do Campus da UFJF. In: SEMINÁRIO DE PÓS-GRADUAÇÃO EM GEOGRAFIA DA UFJF, 3, 2014, Juiz de Fora. Anais... p. 335-347.

PASSOS, Messias M. dos. Biogeografia e Paisagem. 2.ed. Presidente Prudente: PPGE, 2003.

OLIVEIRA, Fernando M.; NUNES, Tatiana, S. Aplicação de protocolo de avaliação rápida para caracterização da qualidade ambiental do manancial de captação (Rio Pequeno) do município de Linhares, ES. Natureza on line, v. 13, n. 2, p. 86-91, 2015.

PLAFKIN, James; BARBOUR, Michel T.; PORTER, Kimberly et al. Rapid bioassessment protocols for use in streams and rivers: Benthic macroinvertebrates and fish. Washington (DC): EPA, 1989.

PINTO, Lilian V.A.; ROMA, Talita N.; BALIERO, Kátia Regina C. Avaliação da qualidade da água de nascentes com diferentes usos do solo em seu entorno. Cerne, v. 18, n. 3, p. 495-505, jul./ set. 2012.

RANGEL, Luana de A.; BOTELHO, Rosângela G.M. Análise ambiental da trilha Sahy-Rubião no Parque Estadual Cunhambebe em Mangaratiba (RJ) por meio de um Protocolo de Avaliação Rápida. Revista Geo UERJ, n. 30, p. 391-418, 2017.

RODRIGUES, Aline Sueli de L.; MALAFAIA, Guilherme; CASTRO, Paulo de Tarso A. Protocolos de avaliação rápida de rios e a inserção da sociedade no monitoramento dos recursos hídricos. Ambi-Agua, v. 3, n. 3, p. 143-155, 2008.

SEAAPI - Secretaria de Agricultura e Pecuária. Rio Rural: Desenvolvimento Rural Sustentável em Microbacias Hidrográficas. Programa de Sustentabilidade e Proteção de Nascentes. Disponível em: microbacias.rj.gov.br/pt/rio-rural\#sthash.XeyFdXyR.dpuf Acesso em: 11 ago. 2015.

SILVA, Elio; TEIXEIRA, José; GOMES, Rui; GOMES, Alberto. Recursos hídricos subterrâneos na Bacia do Rio Uíma, Santa Maria da Feira: um contributo para o ordenamento do território a nível municipal. In: CONGRESSO NACIONAL DE GEOMORFOLOGIA, 7, 2015, Porto. Livro de Atas de Conferência Nacional... Disponível em: https://repositorio-aberto.up.pt/bitstream/10216/81052/2/106328.pdf Acesso em: 1 jun. 2019.

VALENTE, Osvaldo Ferreira; GOMES, Marcos Antonio. Conservação de nascentes: hidrologia e manejo de bacias hidrográficas de cabeceiras. Viçosa: Aprenda Fácil, 2005.

VARGAS, Jancy Rômulo A.; FERREIRA JÚNIOR, Paulo Dias. Aplicação de um Protocolo de Avaliação Rápida na caracterização da qualidade ambiental de duas microbacias do Rio Guandu, Afonso Cláudio, ES. Revista Brasileira de Recursos Hídricos, v. 17, n. 1, p. 161-168, 2012.

Data de submissão: 21/ ago./2018

Data de aceite: 07/ ago./ 2019 